\title{
Perspectives on transit: Potential benefits of visualizing transit data
}

Colin Stewart

School of Urban Planning

McGill University

Suite 400, 815 Sherbrooke St. W.

Montréal, Québec, H3A 0C2

Canada

Tel.: 514-398-4058

Fax: 514-398-8376

E-mail:colin.stewart2@mail.mcgill.ca

Ehab Diab

School of Urban Planning

McGill University

Suite 400, 815 Sherbrooke St. W.

Montréal, Québec, H3A 0C2

Canada

Tel.: 514-398-4058

Fax: 514-398-8376

E-mail: ehab.diab@mail.mcgill.ca

Robert L. Bertini

Department of Civil and Environmental Engineering Portland State University

P.O. Box 751

Portland, OR, 97207 USA

Tel.: 503-725-4249

Fax: 503-725-5950

E-mail: bertini@pdx.edu

Ahmed El-Geneidy

School of Urban Planning

McGill University

Suite 400, 815 Sherbrooke St. W.

Montréal, Québec, H3A 0C2

Canada

Tel.: 514-398-8741

Fax: 514-398-8376

E-mail: ahmed.elgeneidy@mcgill.ca

Word Count: 4490, 12 Figures

For Citation please use: Stewart, C., *Diab, E., Bertini, R., \& El-Geneidy, A. (2016). Perspectives on transit: Potential benefits of visualizing transit data. Transportation Research Record. 


\section{ABSTRACT}

Advancements in information and communication technologies have enabled transit agencies

4 around the world to generate streams of data on a high frequency basis. Increasingly, these 5 agencies are interested in new methods of visualizing these data in order to communicate the 6 results of their planning efforts, operational investments and overall transit performance to 7 decision makers and stakeholders. Most agencies today collect and provide numerous kinds of 8 data, including Google Transit Feed Specification (GFTS) schedule data, automatic vehicle 9 location (AVL) data, and automatic passenger count (APC) data. This paper aims to demonstrate 10 the untapped potential of these data sources; specifically, the paper uses transit data from 11 Montréal, Canada, to generate performance measures that are of interest to both transit planners 12 and marketing professionals. Some of these measures can also help in communicating the 13 positive attributes of public transportation to the community. Performance measures are 14 generated at different scales, including transit-system, neighborhood, route, and stop levels. This 15 paper expands on previous research on transit-performance research and visualization by 16 adopting currently available "big" data resources.

Keywords: bus service, transit data visualization, GTFS, AVL/APC 


\section{INTRODUCTION}

In the past century, collecting data about public transit systems was difficult and expensive. It typically required manual counting of transit metrics - for example, the number of passengers boarding and alighting - which in turn required large numbers of staff to collect this data (1). However, with the advent of digital transit monitoring systems (global positioning systems (GPS), automatic vehicle location (AVL), and automatic passenger counters (APC)), as well as open data such as Google Transit Feed Specification (GTFS), there is currently an abundance of transit-related data available for analysis.

At the same time, concerns over global warming, urban sprawl, and quality of life, plus generational and demographic changes, are making transit an increasingly important part of the public conversation. Transit-related issues frequently dominate the headlines: endless subway debates in Toronto, increasing transit funds in Montréal and deferred maintenance and state of good repair in major U.S. cities (2-4), to name just a few examples. Since major transit projects can run into serious opposition, the need for informed public debate, and for honest and positive images of transit, is more critical than ever. This paper aims to show how the wealth of data gathered by transit agencies can be used to demonstrate transit performance and benefits, either internally in a transit agency or externally to policy makers and the general public through the use of visualization techniques (5). It further provides several methods that can be used to visually support a variety of transit improvement measures.

Much of previous research on transit data visualization and performance has been targeted internally toward transit agency management with a focus on cost efficiency and service effectiveness (6). For example, Levinson (7) primarily addresses transit service reliability, discussing the organizational structures and technology that can be used to ameliorate reliability issues. On the other hand, a limited number of studies focus on visualizing general aspects of transit that can be used to illustrate planning efforts and/or to help planners on negotiating service modification projects with stakeholders. Bertini and El-Geneidy (1) mostly concentrate on generating performance measures at the route and stop levels, using such metrics as route spacing, fluctuations in passenger volumes, average route speed, and schedule adherence. Berkow et al. (8) extend this work, providing additional performance measures and some visualizations using automatically collected AVL/APC data.

By contrast, transit performance measures that are targeted at customers, decision makers or higher level administration tend to concentrate on convenience, comfort, and safety (9). Similarly, most transit information systems convey only the mechanics of how a transit system works, largely through maps and schedules (10). However, many transit agencies also invest in broader marketing that takes a view of the bigger picture-such as advertising that aims to create a positive image of transit (10). This paper, in part, takes its lead from this kind of marketing practice, but also seeks to go beyond it by making greater use of the vast and increasing quantities of available transit data.

The overall objective of this paper is to demonstrate the untapped potential of using commonly available data for transit agencies to generate performance measures that are of interest to transit planners and professionals, which could be used to communicate transit aspects and improvement efforts to the public and decision makers. Thus, the visualizations will focus on more general issues and aspects, rather than one aspect of transit, giving planners a wide variety of methods. While keeping that in mind, the generated visualizations will help planners to 45 negotiate and support the implementation of bus stop consolidation and all-door-boarding plans, 
to illustrate the current network features and changes, and finally, to offer more initiatives to enrich the transit data visualization literature.

\section{DATA AND RESEARCH METHODS}

Montréal, Quebec, is the second most populous metropolitan area in Canada with 3.7 million inhabitants. The Société de Transport de Montréal (STM), the city’s transit service provider, covers 500 square kilometres (200 square miles) and serves 1.8 million people daily. The STM operates 69 kilometres (43 miles) of subway lines, 222 bus routes, and 9,030 stops. In 2011, the STM achieved a new record of 405 million passenger-trips per year. Many of the visualizations in this paper were generated with STM's archived AVL and APC data. STM has equipped a total of 306 buses with this technology; these buses are assigned to varying routes in order to obtain a sample of the entire bus network's operational performance. AVL/APC data are recorded at the stop level, including bus arrival time, departure time, and number of passengers boarding and alighting.

Several visualizations also use STM's GTFS data. GTFS is an increasingly popular open data format (11) used by Google Maps for its transit-trip applications. GTFS data are updated by hundreds of transit agencies around the world (12) and includes transit supply information related to stops, routes, and schedules. The data is represented as a series of text files with comma-separated values; the main file used in this study is stop_times.txt which includes the scheduled arrival and departure times by stop, trip id (which includes route name), stop sequence, and a unique name for each stop. The second file used in this paper is stops.txt which includes the name and coordinates of each stop.

Other data used in this paper comes from a variety of sources. These include Bixi bicycle-share data, DMTI Spatial, and the 2003 Montréal origin-destination (OD) survey. These data sets were processed using Microsoft Excel and Access and then visualized using ArcGIS and ArcScene 10.1 and Adobe Creative Suite 6 (primarily Illustrator).

This research generates performance visualizations at four hierarchical spatial levels. At the system level, the visualizations deal with transit coverage and spread, improvement in system speed, and waiting time at stops. At the neighbourhood level, the interaction between Montréal's night bus service and the Bixi bicycle-share system is explored, as is the relationship between transit service and population density. At the route level, various passenger-performance indicators are analyzed, such as bus type, load factor, route seating capacity, and stop spacing. Lastly, at the stop-level, bus stop demand and headways are examined. For each visualization, the type of data, methods and the visualization purpose will be described.

\section{SYSTEM LEVEL ANALYSIS}

\section{System Coverage}

Catchment areas around transit stops and stations are useful for understanding service coverage. Overlap between catchment areas indicates that an area is served by multiple buses or metros; thus, the level of transit service can be measured by the number of overlapping catchment areas. Figure 1 shows Island of Montréal's overlapping catchment areas. Each catchment area was based on the $85^{\text {th }}$ percentile of the walking distance estimates (524 metres for bus service and 873 metres for the metro) during the morning peak (06:30-09:30). This distance represents the average walking distance to transit service on Island of Montréal during fall 2003, 
1 and is calculated using the 2003 Montréal OD survey and the network analyst extension in 2 ArcGIS.

The map was generated by intersecting 100-by-100 metre grid cells with the network distance service areas (using the network analyst extension in ArcGIS) for each scheduled stop based on the previous discussed distance; the colour of each grid cell corresponds with the number of catchment areas that overlap it. Here, scheduled stop refers to the stops of each bus route rather than the physical stops; thus, if a physical stop serves multiple bus routes, multiple catchment areas were generated. For each route, only one direction was randomly considered for illustration to avoid double counting. Double counting occurs when two transit stops serving the same route are present across the street from each other. This helps create a more accurate illustration of service coverage.

Red denotes areas with high levels of supplied service with more than 136 scheduled stops, indicating that a high level of transit service is within walking distance. The shades from orange to yellow denote areas with medium levels of supplied service ranging between 14 and 136 scheduled stops per cell. The green color represents fewer than 14 scheduled stops per cell, indicating a lower level of transit supply.

This figure can serve two purposes. The first is providing a visual indicator for passengers to understand where concentrations of transit service are present, within a walking distance. Transit availability has been long seen as an important factor in residential and firm location decisions (13). The second is to highlight the transit agency's efforts to provide high 21 levels of service in some neighborhoods.

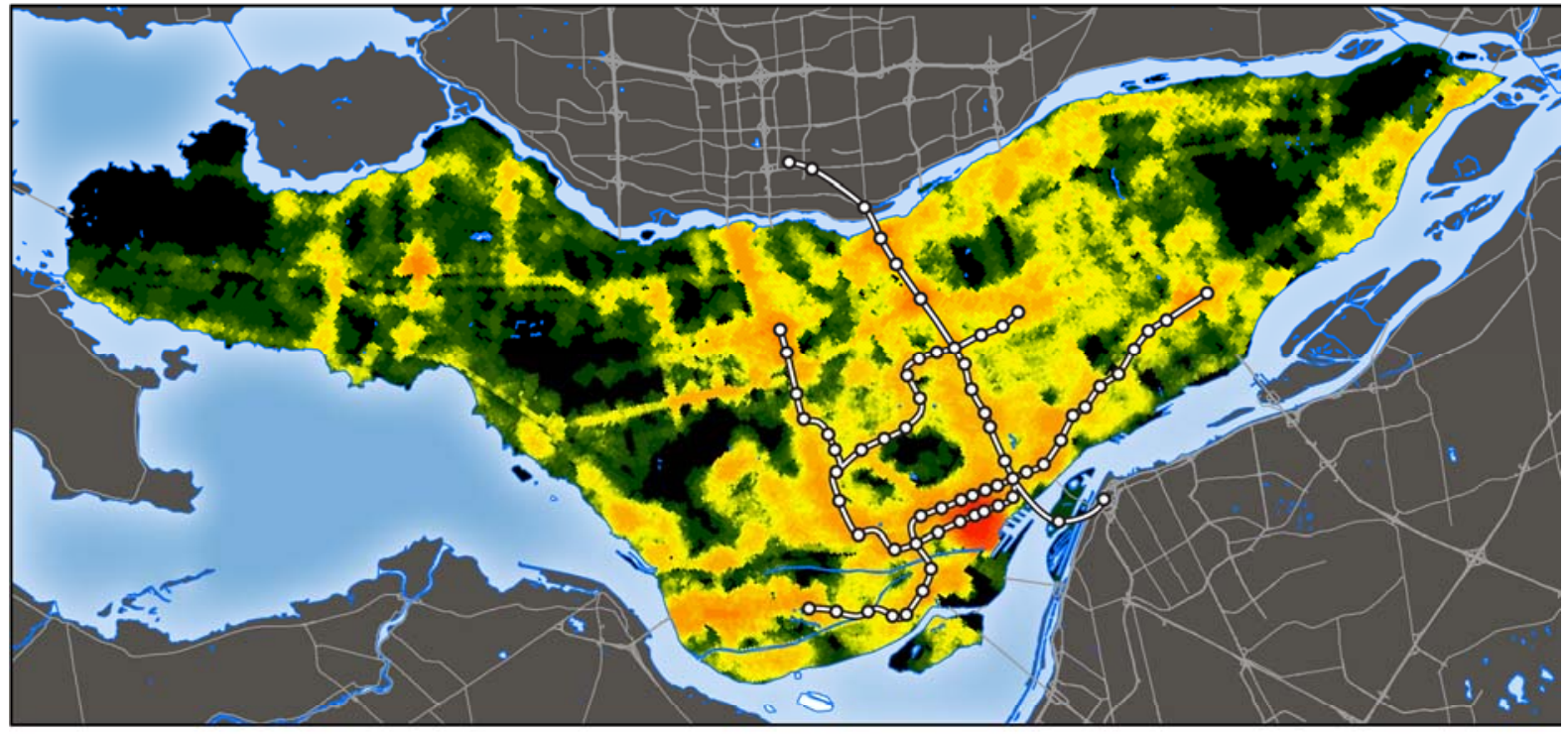

Transit stops with overlapping coverage

\begin{tabular}{|c|c|}
\hline 0 & $14-21$ \\
\hline $1-7$ & $22-36$ \\
\hline $8-9$ & $37-69$ \\
\hline $10-11$ & $70-135$ \\
\hline $12-13$ & $136-272$ \\
\hline
\end{tabular}

So Metro \& metro stops

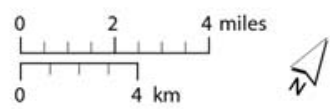

Data source: STM \& DMTI Projection: NAD 1983 MTM 8
FIGURE 1: Overlapping service areas in Montréal using the 85th percentile estimates network buffers 


\section{System Service Span}

Recently, several transit agencies have equipped their transit stops with LCD screens to show various media and transit real time information, cutting down passengers' negative perceptions of waiting time $(14,15)$. STM, for example, has equipped the majority of its metro stations with screens that show real time information about the transit system, as well as different types of entertainment media including news, short reports, and advertisements, with a plan to implement similar systems at selected bus stops.

To date, these LCD screens have not been used to show how Montréal's transit network functions. With that in mind, a video (screenshot shown in Figure 2; http://www.youtube.com/v/1ztMm5xmk3M?version=3\&vq=hd720\&fs=0) was created; this video shows the flow of all buses and metro trains on the island of Montréal over one typical weekday. Using GTFS data from winter 2013, it was possible to identify the scheduled location of buses and metro trains at each minute during the day. The ArcGIS linear referencing tool was used to approximate where each bus and metro was at 30-second intervals; a series of Python scripts were written to automate this process for all 203 STM bus routes and all four metro lines. The final video, which was assembled using Adobe Premiere, Illustrator, and AfterEffects, runs for 96 seconds, with each hour of the day spanning four seconds in the video.

Different modes of transport are assigned different colours, and time is indicated by the clock at the top right. White points indicate a regular bus service, purple points show the frequent bus service (10 minute headways or less), while the other colours show the metro service. The video shows that metro service starts at about 5:30 am and ends around 1:00 am, while the buses run for 24 hours. The video also highlights the complexity of the transit network, the length of service provision over the day, and the daily activity peaks. This short movie can be displayed on the screens at STM's metro stations and bus stops; this will help to increase public awareness about the quality of the service, which is strongly linked to positive increases in passengers' perceptions and overall satisfaction (16).

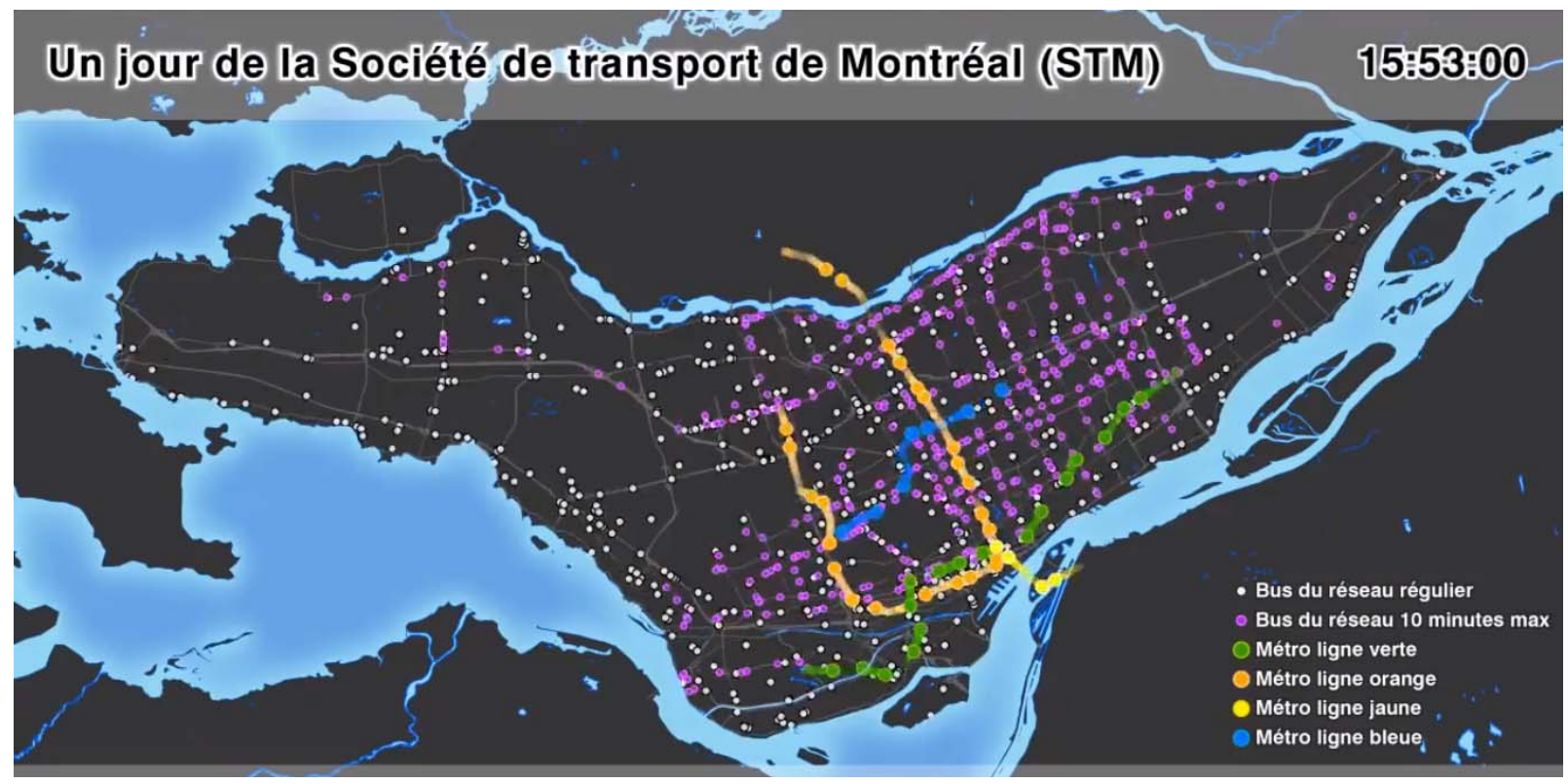

FIGURE 2: An image from a video showing the movement of all buses and metros run by STM over one day. 


\section{Density of Buses}

Figure 3 is a third illustration of one of the transit system fundamentals. The figure shows the density of buses in the Montréal system during the morning peak (06:30-09:30). Darker green indicates fewer buses while brighter red indicates more buses. This figure was generated using winter 2013 GTFS data. As with Figure 1, the city was divided up into 100-by-100 metre grid cells; then, the number of buses entering each cell was calculated, and a kriging function was used to create a smooth interpolated surface.

This figure shows how buses are distributed throughout the city. In the west, the greatest concentrations of buses are around single points—-primarily malls and commuter rail stationswhereas in the middle of the island, buses are increasingly concentrated on entire streets rather than at single points. This reveals a higher degree of bus resources directed in these neighbourhoods. This knowledge could be used, among other system level visualizations, to identify the location of required improvement strategies (e.g. reserved lanes or articulated buses) or high-capacity transit such as BRT or light rail along these corridors.

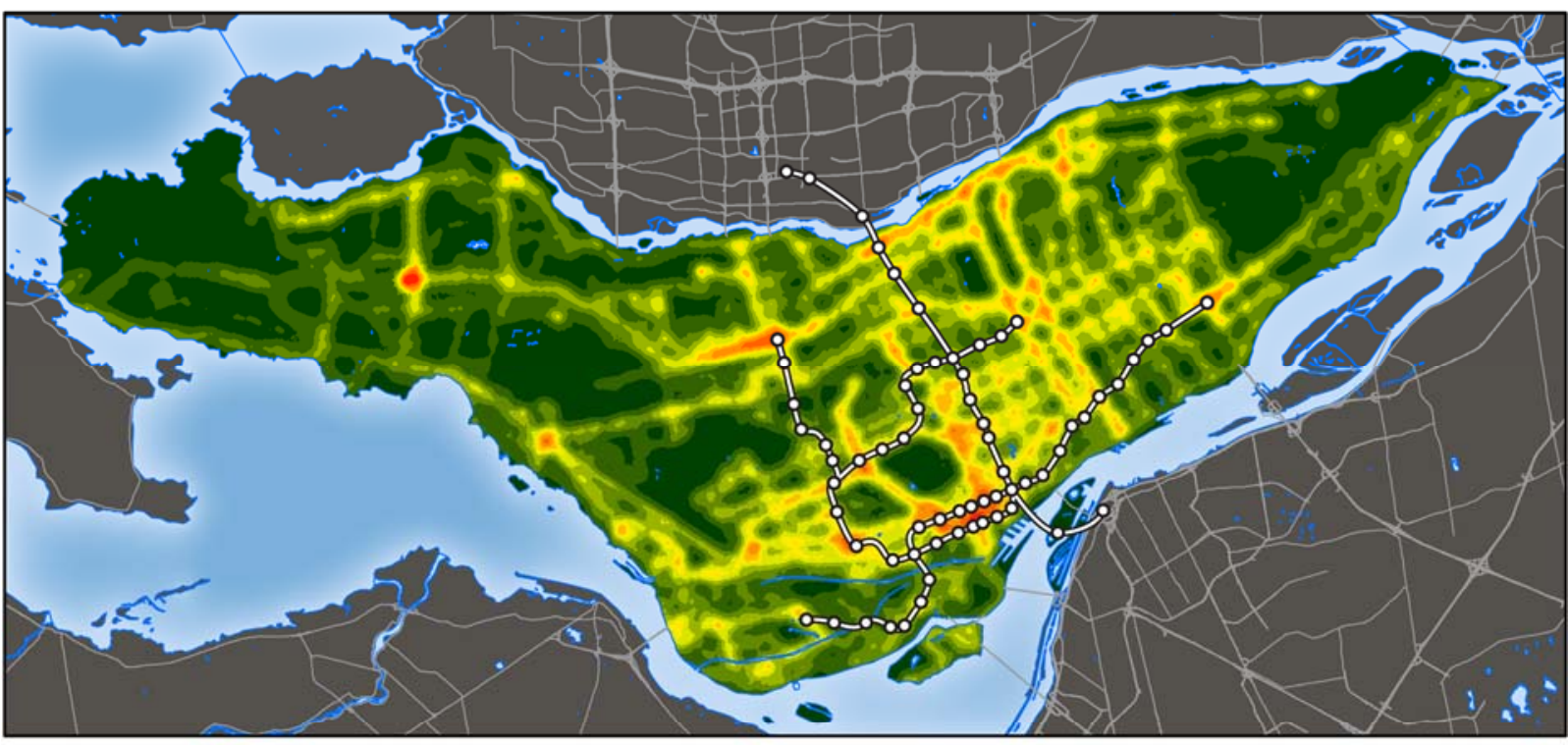

\section{Number of buses in the AM peak}

\begin{tabular}{|l|l|}
\hline $0-5$ & \\
$6-20$ & \\
$66-85$ \\
$21-35$ & $86-110$ \\
& $111-150$ \\
$36-50$ & $151-205$ \\
$51-65$ & $205-370$
\end{tabular}

Con Metro \& metro stops

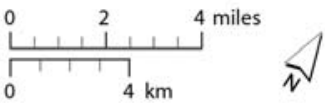

Data source: STM GTFS

Projection: NAD 1983 MTM 8

\section{FIGURE 3: Density of buses in Montréal during the AM peak}

\section{Speed Improvement}

Transit agencies strive to improve their service and, accordingly, to increase ridership and revenue. Using GTFS data for winter 2009 and 2013, it was possible to identify the improvements in bus-route speed and the speeds of the new routes according to schedule. This information may be reported while considering the percentage of on-time buses (1 minute early to 3 minutes late). According to STM, around $83 \%$ of buses were on-time over the past few years, with minor improvements. This would provide an indication that the improvement in speed did not impact the buses' on-time performance. 
Figure 4 shows these changes during the morning peak (06:30-09:30). The speed improvement between winter 2009 and 2013 is represented by red lines. Thicker lines indicate higher segment travel speed and, thus, greater time savings for passengers. The speeds for each route segment were calculated by using GTFS schedule data, and by finding overlaps between route segments. This method was helpful for analyzing the impacts of a reserved bus lane or a traffic-signal priority (TSP) system along a segment shared by more than one route. The maximum segment-speed improvement was approximately $3.2 \mathrm{~km} / \mathrm{h}$, a $10 \%$ speed increase from 2009-2013. This type of map would help planners to visually identify changes in speed and closely investigate the reasons behind the changes.

The figure also shows the speeds of the new routes added between 2009 and 2013. These speeds ranged between 10 and $35 \mathrm{~km} / \mathrm{h}$. These numbers can help passengers understand their travel speeds on the transit network. Furthermore, these numbers may impact commuters' distorted perception regarding transit travel time, since they often report travel times that are longer than reality. Correcting this distortion, and increasing the awareness of travel mode alternatives and their qualities may help increase transit use (17-19).

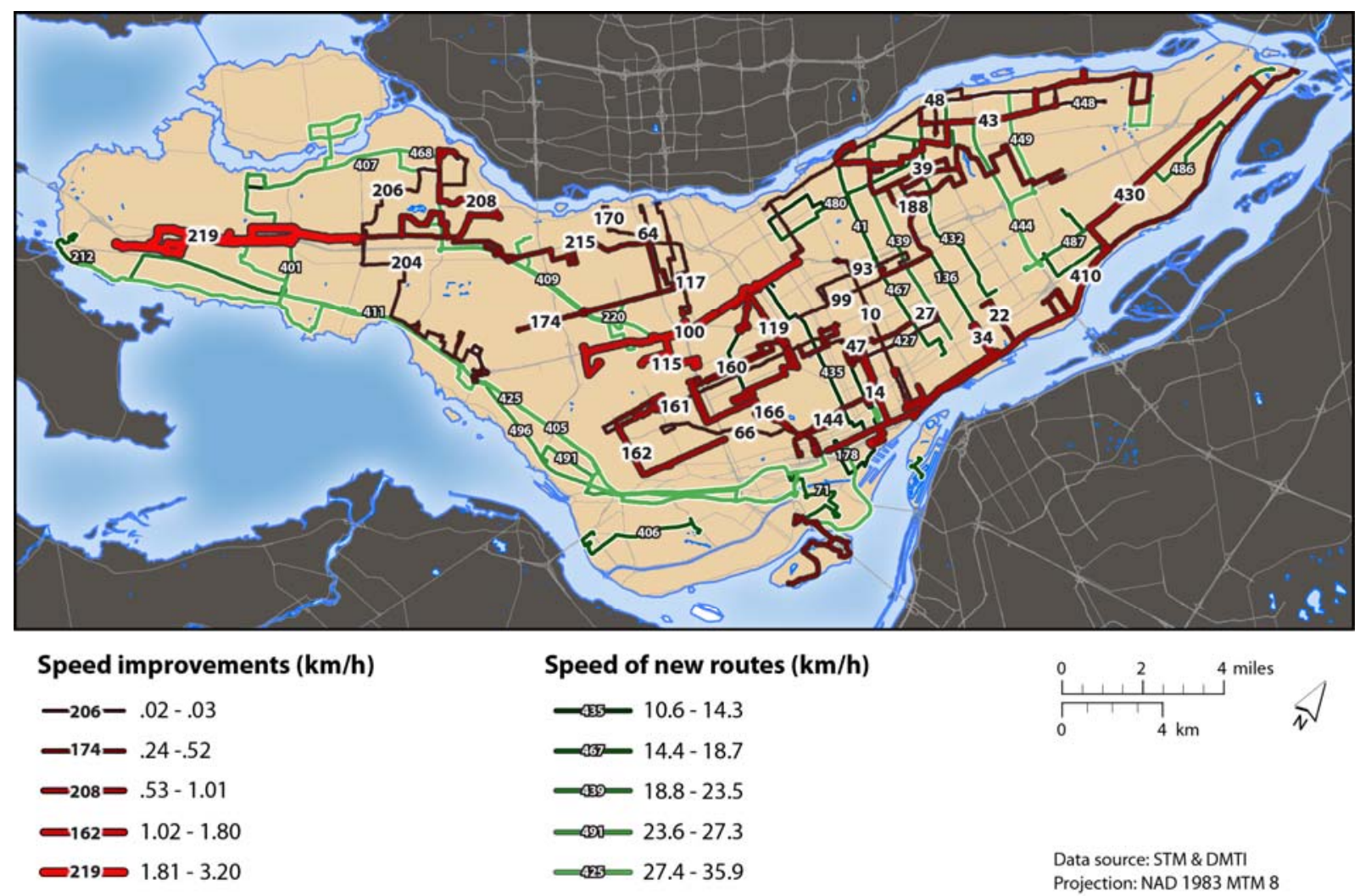

FIGURE 4: Positive changes in speed and new added bus routes in Montréal

\section{Waiting Time at Stops}

Waiting time is one of the most tedious aspects of transit use. While waiting, passengers are exposed to adverse weather conditions and the surrounding environment while being stressed by waiting anxiety (20-22). Research has found that the time spent waiting is perceived to be two to three times more valuable than that of in-vehicle travel time (23); it has also been reported that transit users prefer to walk farther distances than to wait longer at stops (24).

Figure 5 shows the average waiting time at the system level for Montréal during the morning peak (06:30-09:30). Mean bus wait times were derived from winter 2013 GTFS data, 
and were calculated by halving the headway for frequent routes, and by assigning a value of eight minutes for those with headways exceeding 15 minutes. The logic here is that on routes with sub-15-minute frequencies, passengers just arrive at their stop when it suits them, and then wait on average half the headway; by contrast, on less frequent routes, passengers typically consult schedules instead (25-27). For the figure, bus stops that served multiple routes were duplicated so that waiting time values were included for each route. After all the waiting times were calculated, a surface was interpolated using the stops' scheduled headway values, creating a continuous, smooth surface. The kriging function in ArcGIS was used to create the surface, in which the surrounding measured values were weighted (based on distance between the measured points) to derive a predicted value for an unmeasured location. This map is useful, from a passenger's point of view, for spatially linking their expected waiting time to where they live or work. It should be noted that this figure, as well as figure 1 and 4 , represent the three main components of transit trip from users' point of view (i.e., walking, in-vehicle, and waiting time).

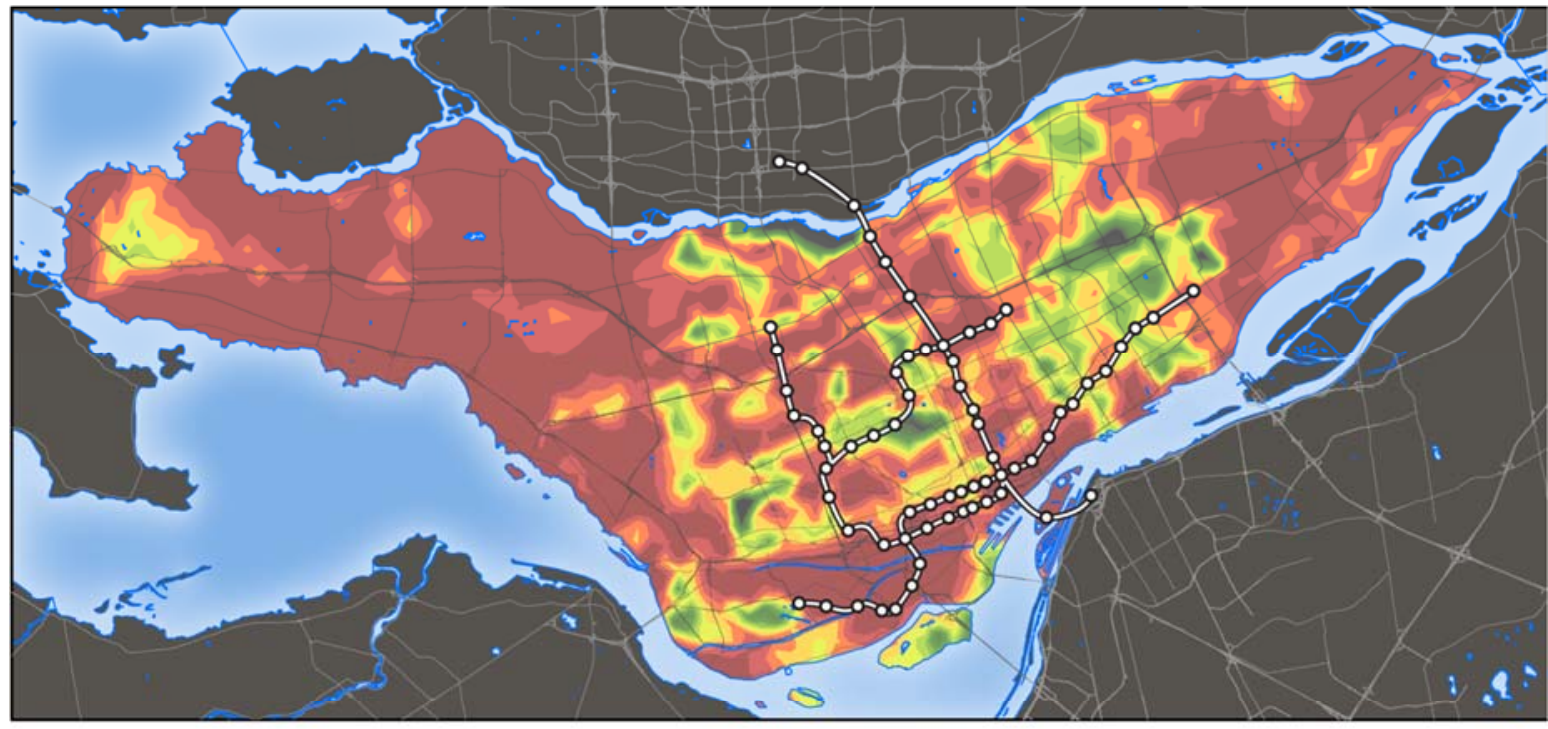

Average bus-stop wait time (minutes)

\begin{tabular}{lll}
\hline $1.9-4.1$ & $\square$ & \\
\hline & $6.6-6.7$ \\
$4.2-4.9$ & \\
$5.8-7.0$ \\
$5.0-5.7$ & \\
$5.8-6.1$ & $7.1-7.2$ \\
$\square .3-7.6$ \\
$6.2-6.5$ & $>7.7$
\end{tabular}

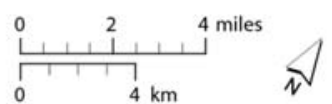

\& Metro \& metro stops

FIGURE 5: Wait time at bus stops in Montréal winter 2013

NEIGHBORHOOD LEVEL

Sometimes it is important to show how different transport modes (or options) are working together at smaller scales than at the system-wide level. This is true when considering the Bixi bicycle-share network, which only covers an area directly surrounding the downtown core of Montréal. Unlike the metro network, Bixi does not have a schedule; it is available to riders all day and night. Thus, Bixi can be an effective option for transit riders after the metro closes (1:00 am on Sundays and weekdays; 1:30 am on Saturdays). The other main option for transit riders in this time period is the night-bus network. Depending on the situation, Bixi may 
Figure 6 shows the accessibility to both of these services when the metro is no longer operating in the evening. Using accessibility measure is common on the literature to generate maps(28). The figure was derived with data from STM GTFS and bixi.com, and was created by measuring the level of accessibility of each postal-code area (typically equivalent to a blockface) to night buses and to Bixi bicycles. For each postal code, the distance (dist) to each nightbus stop ( $i$ ) and Bixi station ( $j$ ) within walking distance (400 metres (a quarter mile) along the pedestrian network) was determined using ArcGIS. Then, the following formulas were used to calculate two accessibility scores for each postal code.

$$
\text { Accessibility }_{\text {bus }}=\sum_{i} \frac{\text { night Buses Per } \text { Hour }_{i}}{\text { dist }_{\text {bus }}{ }^{2}}
$$

$$
\text { Accessibility }_{\text {bixi }}=\sum_{j} \frac{\text { mean Available Bixi Bicycles At Night }}{j}
$$

The accessibility maps for each of the above two measures were visually overlaid to show where night-bus accessibility (blue) overlaps night-Bixi accessibility (yellow); the areas of overlap are shown in green. What the figure ultimately shows is that between the night-bus network and the Bixi network, a large proportion of Montréal near downtown is completely covered. This figure is also of use to people who need to get home after the metro closes and who need to decide whether bus or Bixi is the most suitable mode. This method of analysis could be extended to other cities or modes. Planners may use this figure to identify neighborhoods that are underserved at night.

21

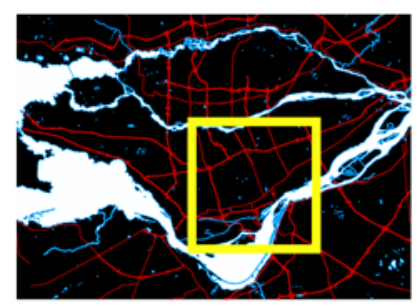

Night-time transit accessibility

Lowest Highest

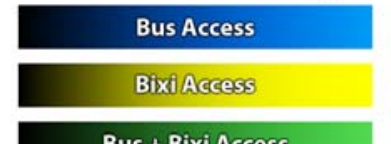

Bus + Bixi Access
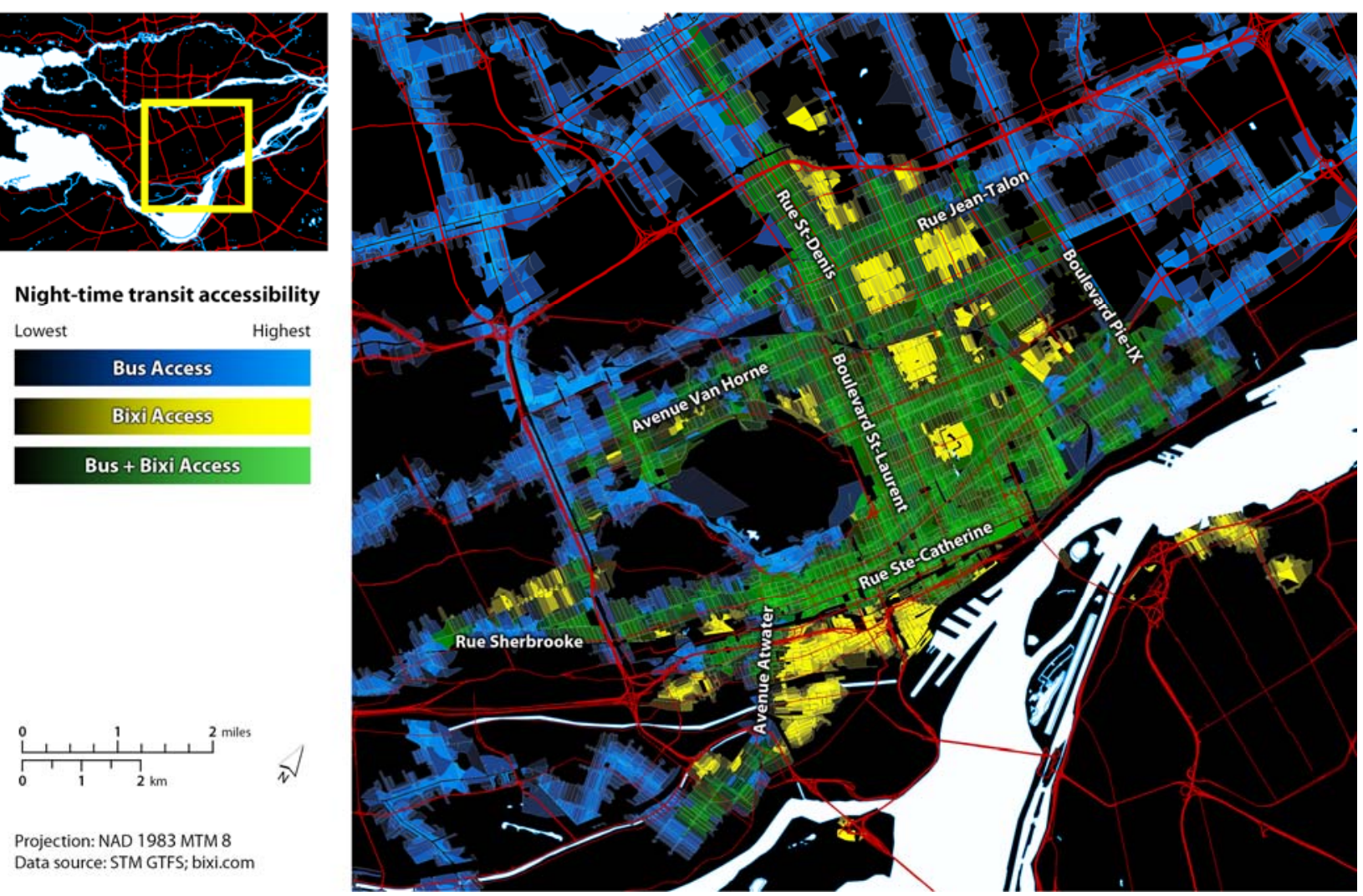

Data source: STM GTFS; bixi.com

\section{FIGURE 6: Transit accessibility after the Montréal Metro closes.}




\section{Passenger Activity in Different Boroughs}

Understanding passengers' activity changes over a day is important for transit agencies in order to provide better service for a reasonable cost. Different boroughs in the city may have completely different transit patterns over a day. Figure 7 shows the difference in passenger activity between three boroughs of Montréal: Pointe-Claire, a suburban borough in the west of the island of Montréal; Ville-Marie, the downtown borough of Montréal; and Plateau-MontRoyal, a mixed-use borough directly northeast of downtown. From each of these boroughs, a representative bus stop was chosen using the following method: the total daily passenger activity (boardings and alightings) of each bus stop in each of these three boroughs was calculated, and the bus stop in each borough with the median level of activity was selected. The hourly activity of these three stops was then plotted over a day.

As the figure shows, different patterns can be identified over the day. The figure shows that the downtown borough, Ville-Marie, despite being the "core" of the city, has significantly lower bus usage than Plateau-Mont-Royal at all periods of the day other than the morning peak; also, activity in Plateau-Mont-Royal continues late into the night. Passenger activity downtown (Ville-Marie) peaks sharply during the morning hours, then has two smaller peaks in the afternoon before dropping off completely in the evening. In the suburban borough (PointeClaire), there are two waves of morning commuters at 6 am and $8 \mathrm{am}$, but after that, activity is fairly low throughout the day. The figure can help planners visually identify variation over a day. It also shows the population density per square kilometre for each borough. This can be linked to the variation of demand to justify increasing the offered service during a particular period.
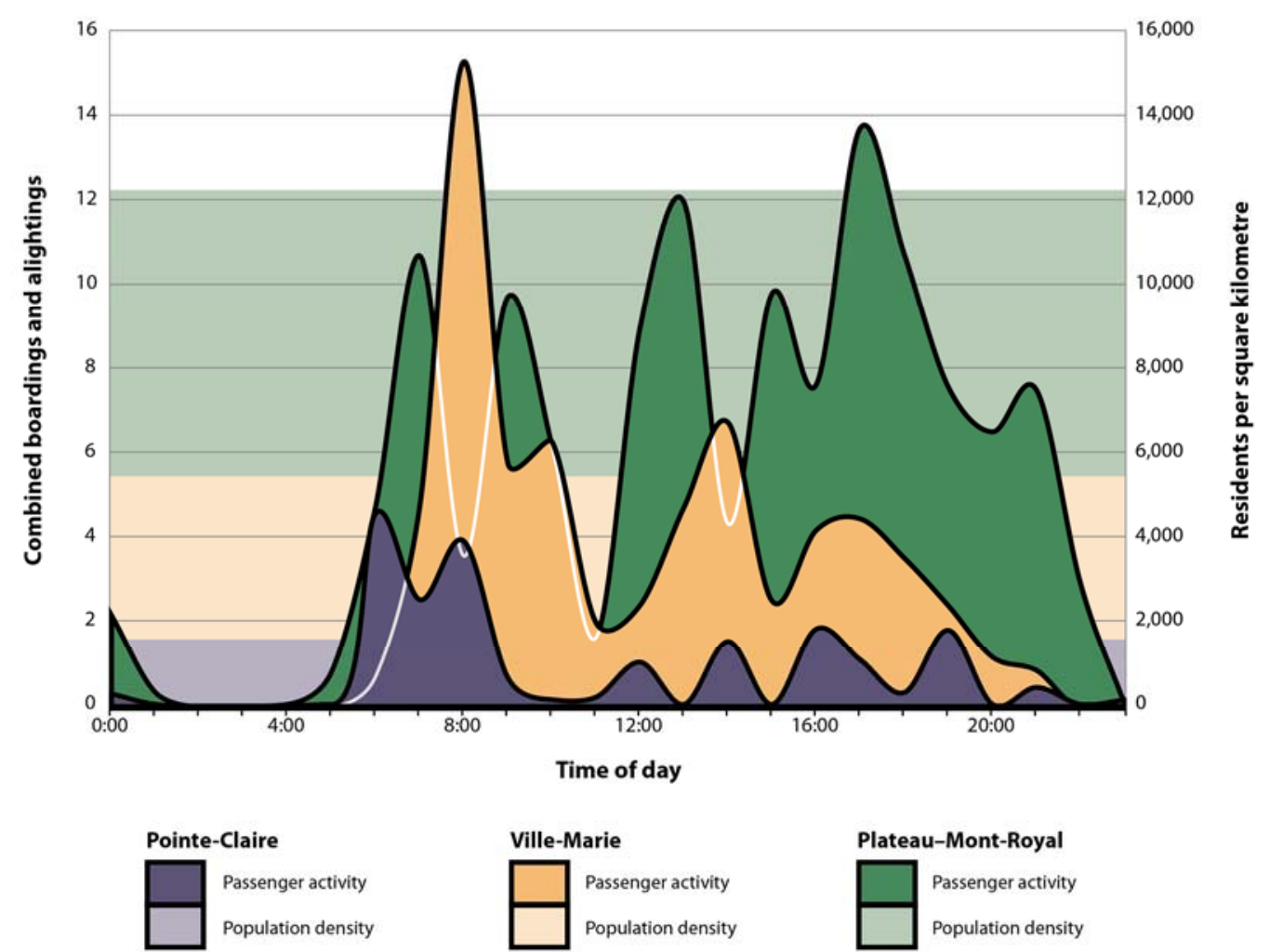


\section{ROUTE AND SEGMENT LEVEL Route Seating Capacity}

Viewing transit data at the route level can help planners better understand the characteristics and demand changes along a specific route, and provide passengers with a better idea about how their most commonly used routes work. In this section, the majority of visualizations have been generated using STM's AVL/APC data.

Figure 8 presents a 3D illustration of the seating capacity of route 67 northbound. This route runs for $9.4 \mathrm{~km}$ (5.8 miles) along Boulevard Saint-Michel, and connects to two metro stations east of downtown Montréal. The average bus load factor-that is, the percentage of full seats on the bus-is represented by translucent vertical bars, and the average daily boarding and alighting (2013) is shown with green and blue columns, respectively. The figure was generated using STM’s AVL/APC data collected between January and May of 2013 (around 50,000 records); bus load factors were calculated by determining the number of passengers boarding and alighting at each stop, in conjunction with the number of seats installed on the specific buses used. The data were displayed using ArcScene 10.1.

It is clear from the figure that the highest levels of boardings are around the metro stations. The highest levels of alightings are at the Saint-Michel metro station and at the northbound terminus. The key policy element in the figure, the load factor, shows an increase from about $65 \%$ near the Joliette metro station to a peak of $76 \%$ near the Saint-Michel metro station (shown in red); it then drops off as the route continues north. Transit planners can use images like this to suggest and support short-turn route policies to decrease crowding and increase passenger comfort. It can also be displayed to passengers to help them decide at which stop they should board their bus in order to increase their chance of getting a seat.

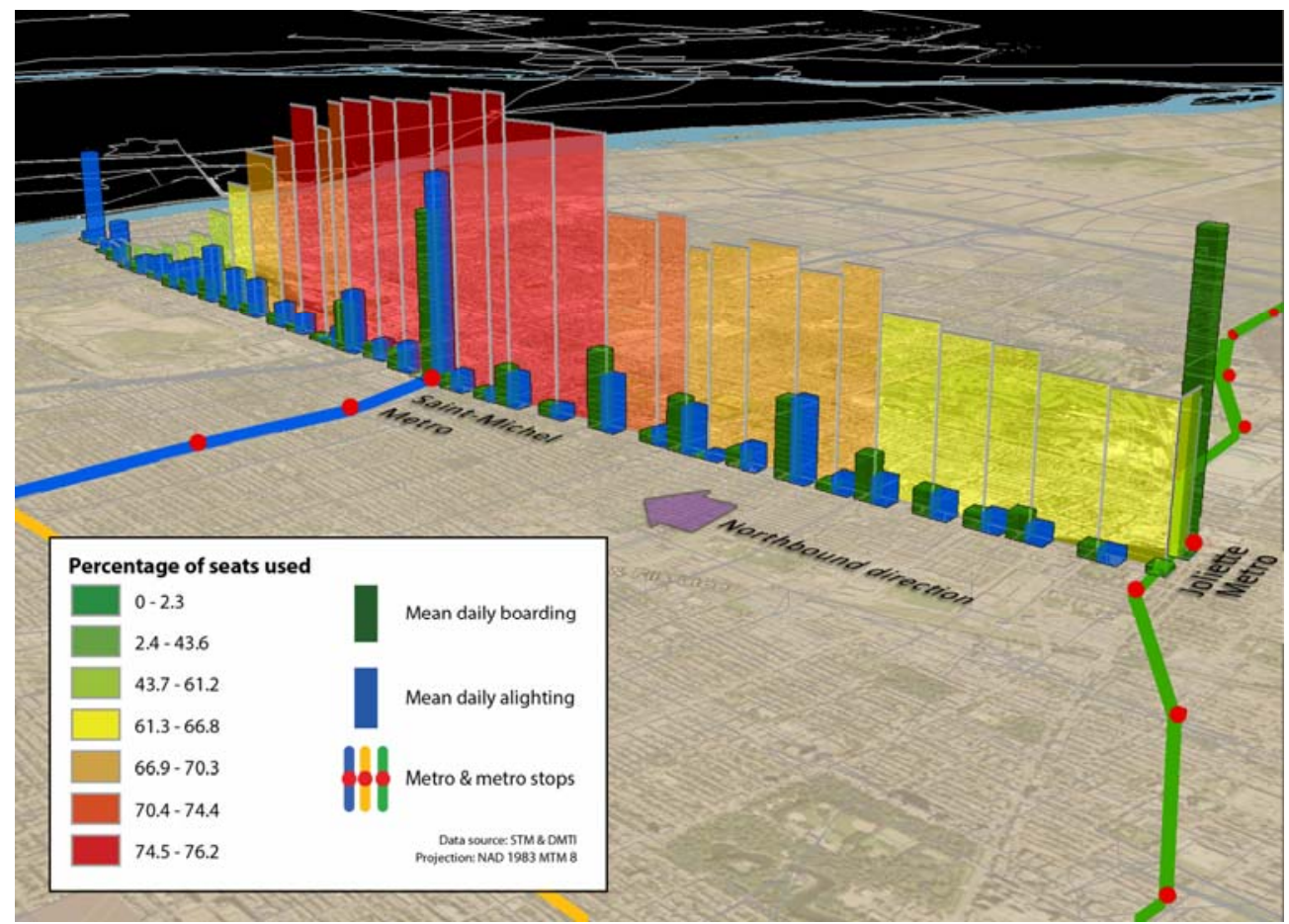
alighting. 
1 Bus Stop Consolidation

Bus-stop consolidation can be one of the most effective strategies for increasing system efficiency and decreasing running times (29). Bus-stop consolidation can be defined as decreasing the number of stops being served along a route while maintaining customer accessibility to the route. However, the decision of whether or not to consolidate bus stops is more complex from the passengers' point of view; they must make a trade-off between the potential increase in their walking distance with the potential decrease in both their travel time and waiting time. These decreases have been linked to increases in ridership and rider satisfaction levels (30-32).

Figure 9 presents a conceptual GIS planning approach for bus stop consolidation along Route 57. A 400-metre (quarter-mile) buffer using network distances was defined around each bus stop; this is a standard-size catchment area for buses (33-35). Next, these buffers were intersected by 20-metre (66-foot) grid cells. For each grid cell, the number of intersected service areas was calculated, representing the number of stops serving that cell. As seen on the left side of Figure 9, substantial redundancy and overlaps in the bus stop service areas exist on the southern end of the route.

The right side of Figure 9 proposes an altered route with reduced redundancy. To create this figure, AVL/APC data for the route from 2010 was used: 30,000 stop level records were analyzed, and the stops with the lowest morning passenger activity (boarding and alighting) were identified as candidates for consolidation. Ultimately, nine of the thirty-one stops were recommended for removal, and the greatest number of overlaps per cell decreased from nine to five.

Such consolidation would substantially decrease the bus running time and passengers’ waiting time, while having minimal impact on passengers' accessibility to the route. More specifically, each skipped bus stop decreases bus running time by 10 seconds (36-39) and its variation by $0.1 \%$ on average (37). Running time savings along the route can reach 90 seconds (1.5 minutes) on average, which represents $8 \%$ of the total trip running time along the route (18 minutes). This means that STM would be able to add a new trip after every 13 trips which would increase bus frequency and decrease passengers' waiting time, while reducing the variation in service (e.g. recovery time at layover stops) by $0.9 \%$ on average. Figure 9 , along with these results, can help planners to communicate and demonstrate the benefits of bus stop consolidation measures. 

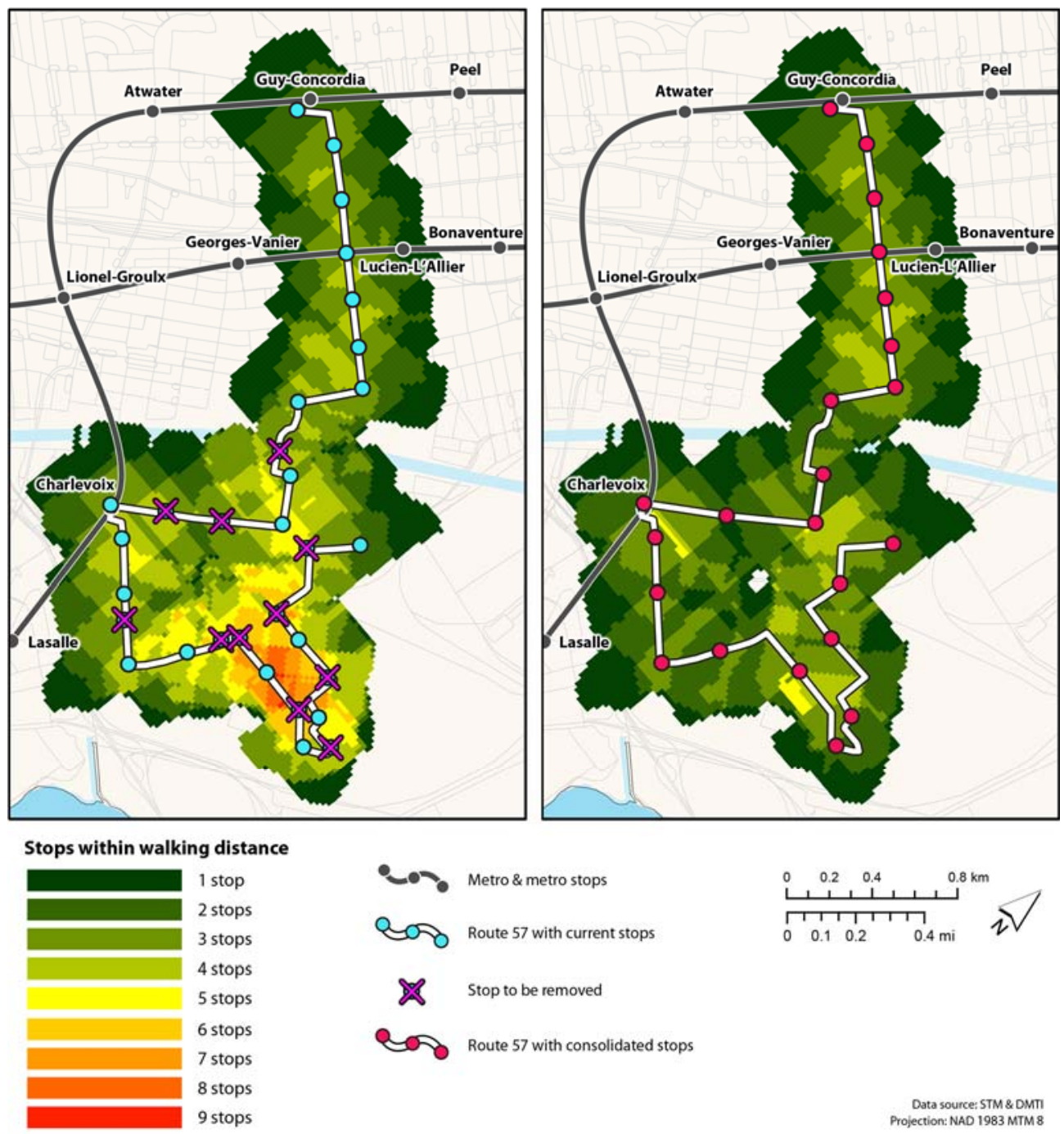

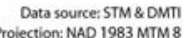

FIGURE 9: Route 57 bus stop consolidation concept. Boarding, Alighting, and Route Direction

All-door bus boarding - allowing passengers to board buses through any door on the vehicle-is becoming an increasingly widespread practice. There are many ways of implementing all-door boarding: it can be allowed on every bus in a transit system (systemlevel), on specific bus routes (route-level), or at specific bus stops (stop-level). Different patterns of passenger boarding make different implementations more appropriate than others; the ideal implementation strikes a balance between serving as many high-boarding stops and as few lowboarding stops as possible, as well as being simple and consistent for the public to understand.

11 To facilitate acceptance of a new all-door boarding policy, it is necessary to communicate to the public and decision makers why particular implementations are chosen. Figure 10 shows the daily boardings and alightings at each stop along Route 165, one of the busier routes in Montréal. The figure employs AVL/APC data obtained in 2013 (about 40,000 records), and was created manually in Adobe Illustrator. It shows a schematic diagram of the stops along the route, allowing for a more immediate understanding of the passenger-activity figures than a standard graph. The northbound direction of the route, on the top half of the figure, has high boarding levels at just two stops, while having low boarding levels at its other stops. By contrast, the 
southbound direction, on the bottom half of the figure, has no individual stops with such high boarding levels, but instead has moderate levels of boarding spread across about a quarter of its stops. Over the whole day, the two directions see similar levels of boarding (10,729 northbound; 9,133 southbound). The boarding pattern seen in the northbound direction could justify all-door boarding at its two main stops only (a stop-level implementation). Conversely, this figure could make the case for a route-level implementation of all-door boarding, either in the southbound direction only, or on the full route.

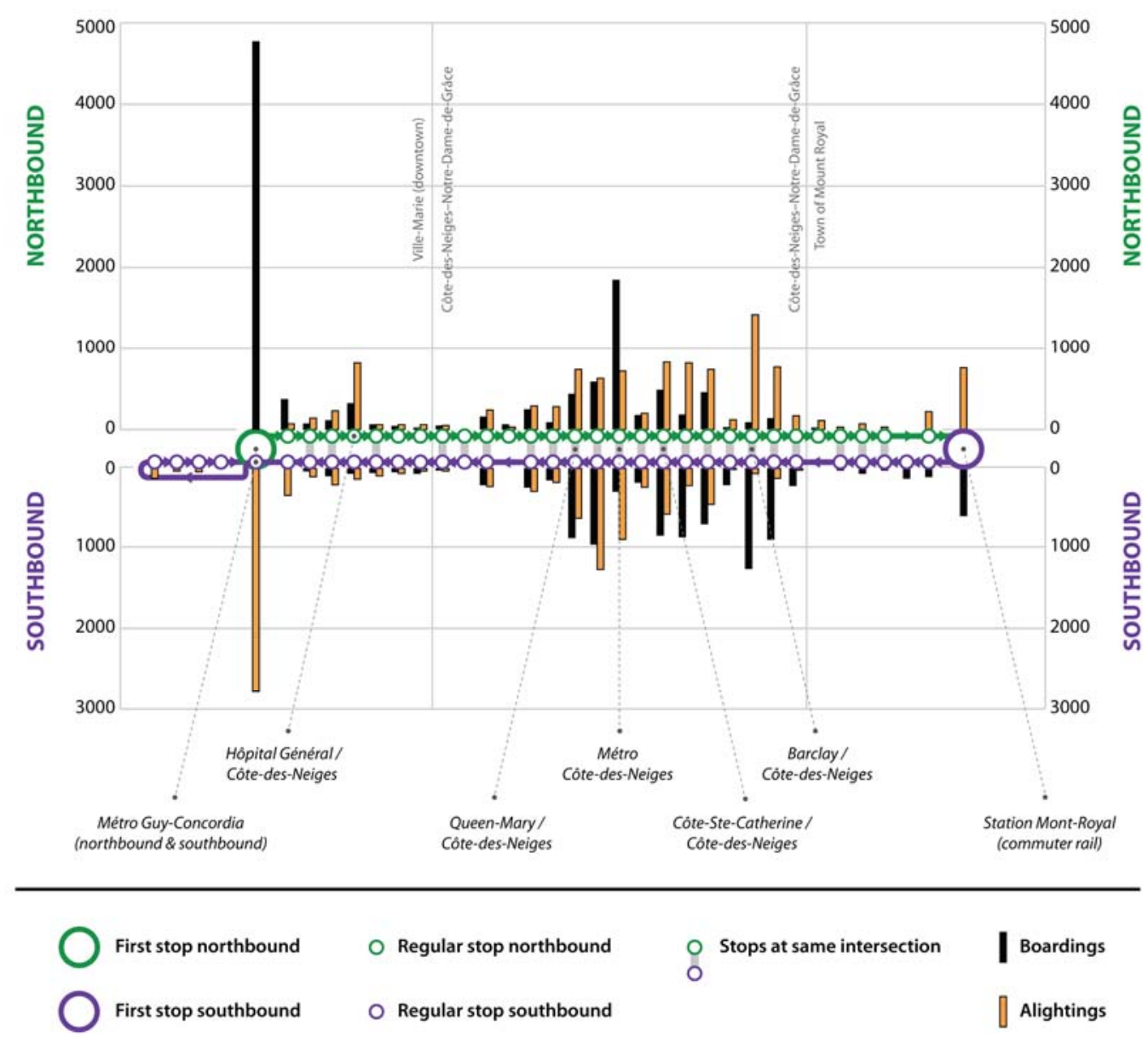

FIGURE 10: Daily passenger activity on Route 165

\section{BUS STOP LEVEL}

\section{Demand at Bus Stop}

Finally we turn to stop-level visualizations. Figure 11 presents a diagram and a map that illustrate the variation of demand and dwell times at three bus stops along Montréal's northbound Route 67 throughout the day. Using AVL/APC data (mentioned in Figure 8) for the route, the average dwell time per hour and the average total passenger activity per trip at each stop were calculated. Three consecutive bus stops were selected with an average spacing of 170 metres (550 feet). The color green represents the stop at Rosemont Street, while purple and orange represent the stops at Dandurand and Holt, respectively. Dwell times are represented with lines, while the average total passenger activity per trip is shown with vertical bars. This figure shows that passenger activity at the Holt stop is consistently much lower than at the other two stops; as such, Holt is an excellent candidate for bus stop consolidation. Removing this stop would 
eliminate the portion of dwell time required by the bus for accelerating and decelerating at this stop, thus decreasing the route's overall running time. This figure can be used in conjunction with Figure 9 to support bus stop consolidation projects and to show the overall benefits, helping planners to visualize their service enhancement plans.
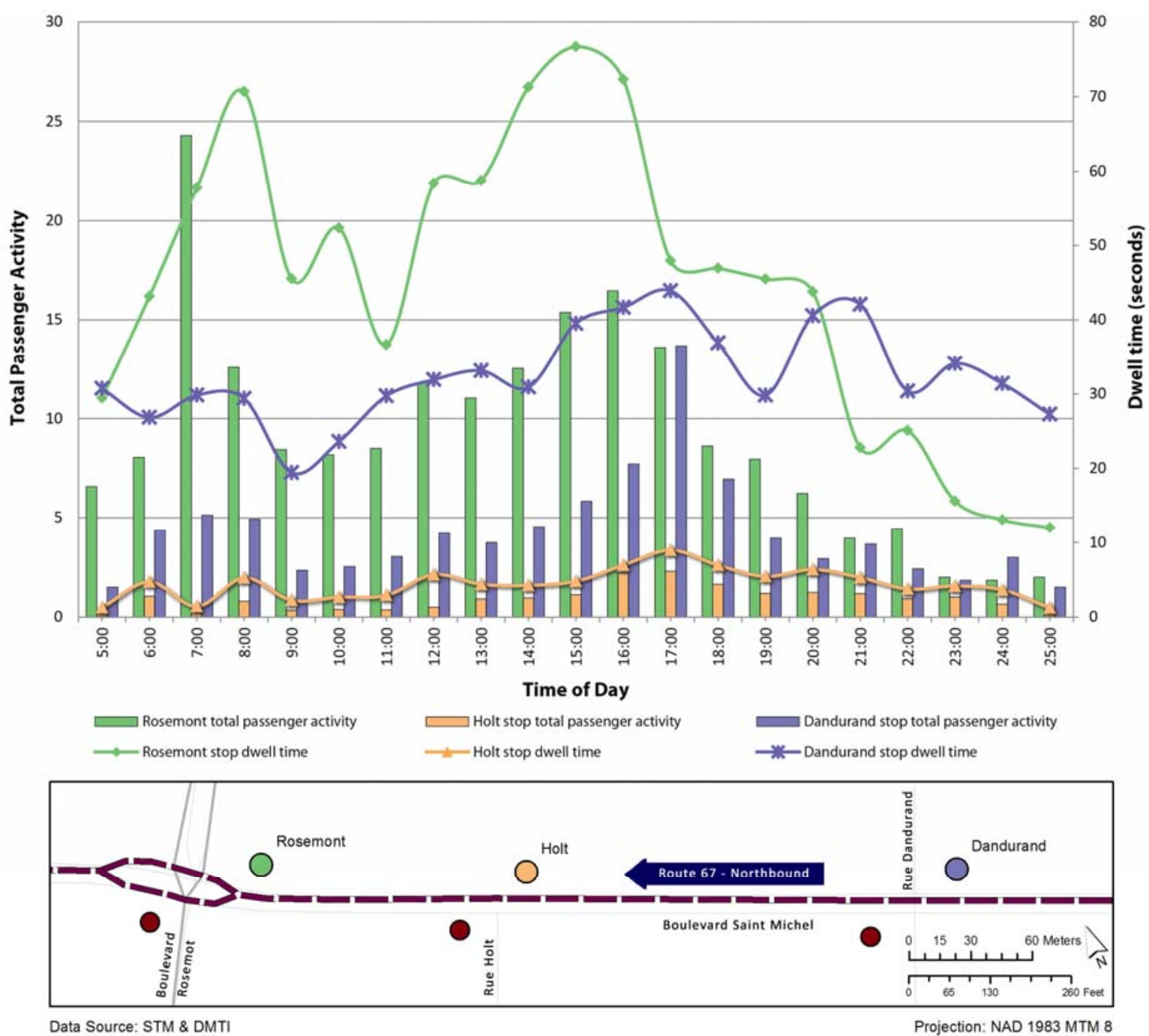

\section{FIGURE 11: Variation of demand and dwell time at three consecutive bus stops}

\section{Combined Benefits}

At stops that are served by more than one route in the same direction (e.g. local and express service), combined schedules can play a role in showing the real benefits that passengers experience. Figure 12, which was generated with 2013 GTFS data, shows the combined frequencies of Routes 67 and 467 at the Saint-Joseph Boulevard northbound stop. The $x$-axis represents time, and the $y$-axis represents buses per half hour. The 467, which is a frequent express service running from 7:00 am to 7:00 pm, is shown in purple, while the 67, a parallel local all-day service, is shown in orange. The green area represents the combined headway, which in turn represents passengers' actual experience of bus frequency. According to recent 
users (with a confidence interval of 5.3\%) indicated that they used both routes equally (36). As such, knowing the combined frequency by time period is more useful than knowing the schedules for each individual route. Planners may use such a figure to demonstrate and support transit projects e.g. implementing new limited stop service.

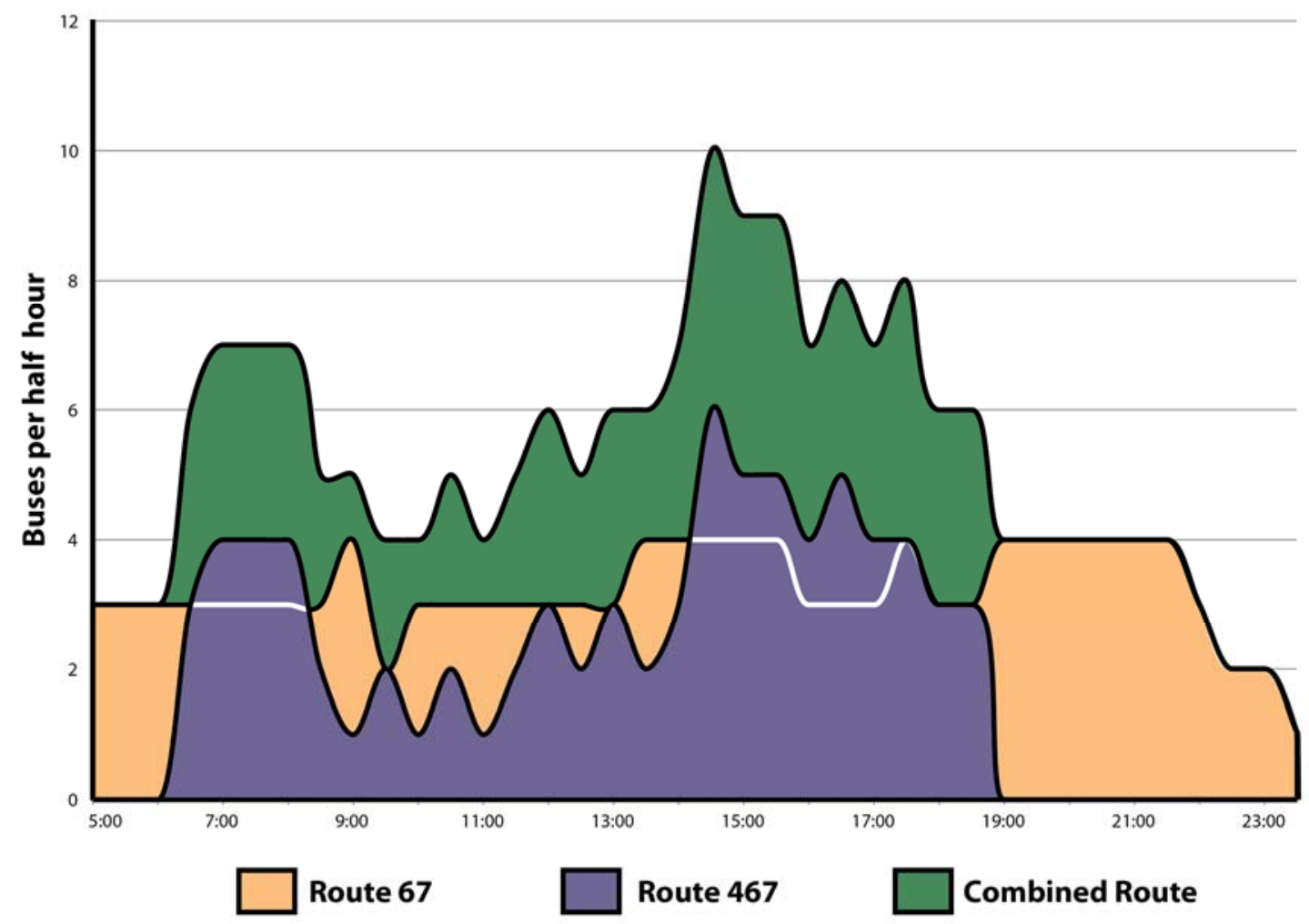

FIGURE 12: Routes 67 and 467 combined bus schedule at Saint-Joseph Northbound stop

\section{CONCLUSION}

Data visualization is a powerful tool for communicating with planners, decision makers and the public and can take advantage of "big data" in the transit industry. The main objective of this paper was to move beyond the generation of internally focused performance measures that relate to transit-agency operations (e.g. passenger miles), and to instead introduce new performance measure visualizations that demonstrate general aspects of transit, helping planners to negotiate and support service-change projects. This research used various types of common data that most transit agencies collect and provide, including GTFS and AVL/APC data.

Performance measures were generated at the system, neighborhood, route and stop levels, following a hierarchical spatial approach. The system-level visualizations dealt with transit coverage and service spread, system improvement in speed, and waiting time at stops. The neighbourhood-level visualizations covered the integration between night-bus service and bicycle-sharing, and the fluctuations of transit demand over the day. The route-level visualizations focused on route seating capacity, passenger activity by direction, and on communicating the potential impacts of implementing stop consolidation. Finally, the stop-level visualizations looked at variation of bus-stop demand and dwell time, and at combined headways on parallel routes. Several of these figures can be used together to help planners visualize their

25 plans at different spatial levels. 
One important use of these "big data" tools is to demonstrate and test different ways of 2 conveying and communicating positive messages about changes or potential changes in service 3 to stakeholders and decision makers. Transit-data visualization techniques are capable of 4 displaying multiple transit performance measures and datasets simultaneously. Thus, these 5 techniques can illustrate important transit concepts to more general audiences with relative ease; 6 furthermore, the required data to create these images is readily available, as it is already being 7 collected and archived. The value of an open framework for streaming "big data" being 8 generated by transit agencies cannot be overstated. Finally, efforts presented in this paper to 9 incorporate new data-visualization techniques will help facilitate communication between 10 planners, and increase public awareness of transit service attributes and improvements, thus 11 helping transit planners to justify their decisions. This increased public awareness may in turn 12 help to increase public involvement, satisfaction, and loyalty toward transit agencies.

\section{ACKNOWLEDGEMENTS}

15 The authors gratefully acknowledge Michel Tremblay, Anna Guinzbourg, and Sébastien Gagné

16 from the Société de transport de Montréal (STM) for providing the data used in the paper and for 17 their feedback and support during this study. This research was funded by the Natural Sciences 18 and Engineering Research Council of Canada.. 
1. Bertini, R. and A. El-Geneidy. Using Archived Data to Generate Transit Performance Measures. Transportation Research Record, Vol. 1841, 2003, pp. 109-119.

2. CBC News. Toronto Councillors Support Scarborough Subway Extension http://www.cbc.ca/news/canada/toronto/story/2013/07/17/toronto-subway-scarborough.html Accessed 21st july. 3. Cheadle, B. Big City Mayors Seek More Federal Funds for Social Housing, Public Transit http://montreal.ctvnews.ca/big-city-mayors-seek-more-federal-funds-for-social-housing-publictransit-1.1705823\#ixzz2ymJWuuiH Accessed 20 April.

4. Snyder, T. Obama Administration Pushes for Transit Maintenance http://usa.streetsblog.org/2011/06/13/obama-administration-pushes-for-transit-maintenance/ Accessed 20 April.

5. Avelar, S. Visualizing Public Transport Networks: An Experiment in Zurich. Journal of Maps, Vol. 4, No. 1, 2008, pp. 134-150.

6. Fielding, G. Managing Public Transit Strategically: A Comprehensive Approach to Strengthening Service and Monitoring Performance. Jossey-Bass Publishers, San Francisco, 1987.

7. Levinson, H. Supervision Strategies for Improved Reliability of Bus Routes. Transportation Research Board, Washington, DC, 1991.

8. Berkow, M., A. El-Geneidy, R. Bertini and D. Crout. Beyond Generating Transit Performance Measures: Visualizations and Statistical Analysis Using Historical Data. Transportation Research Record, Vol. 2111, 2009, pp. 158-168.

9.

10. Vuchic, V. Urban Transit: Operations, Planning, and Economics. John Wiley \& Sons, Inc., Hoboken, NJ, 2005.

11. Lee, S., M. Hickman and D. Tong. Stop Aggregation Model. Transportation Research Record: Journal of the Transportation Research Board, No. 2276, 2012, pp. 38-47. 12. GTFS Data Exchange. General Transit Feed Specification (Gtfs) Data Exchange http://www.gtfs-data-exchange.com/ Accessed July 1st.

13. Levinson, D. and K. Krizek Planning for Place and Plexus: Metropolitan Land Use and Transport. Routledge, New York, 2008.

14. Dziekan, K. and A. Vermeulen. Psychological Effects of and Design Preferences for RealTime Information Displays. Journal of Public Transportation, Vol. 1, 2006, pp. 71-89. 15. Mishalani, R., M. McCord and J. Wirtz. Passenger Wait Time Perceptions at Bus Stops: Empirical Results and Impact on Evaluating Real-Time Bus Arrival Information. Journal of Public Transportation, Vol. 9, No. 2, 2006, pp. 89-106.

16. dell'Olio, L., A. Ibeas and P. Cecín. Modelling User Perception of Bus Transit Quality. Transport Policy, Vol. 17, No. 6, 2010, pp. 388-397.

17. Garvill, J., A. Marell and A. Nordlund. Effects of Increased Awareness on Choice of Travel Mode. Transportation, Vol. 30, No. 1, 2003, pp. 63-79.

18. Rose, G. and E. Ampt. Travel Blending: An Australian Travel Awareness Initiative.

Transportation Research Part D: Transport and Environment, Vol. 6, No. 2, 2001, pp. 95-110. 19. Kenyon, S. and G. Lyons. The Value of Integrated Multimodal Traveller Information and Its Potential Contribution to Modal Change. Transportation Research Part F: Traffic Psychology and Behaviour, Vol. 6, No. 1, 2003, pp. 1-21. 
20. Cervero, R. Transit Pricing Research: A Review and Synthesis. Transportation, Vol. 7, No. 17, 1990, pp. 117-139.

21. Lam, W. and J. Morrall. Bus Passenger Walking Distances and Waiting Times: A SummerWinter Comparison. Transportation Quarterly, Vol. 36, No. 3, 1982, pp. 407-421.

22. Daskalakis, N. and A. Stathopoulos. Users' Perceptive Evaluation of Bus Arrival Time Deviations in Stochastic Networks. Journal of Public Transportation, Vol. 11, No. 4, 2008, pp. 25-38.

23. Mohring, H., J. Schroeter and P. Wiboonchutikula. The Value of Waiting Time, Travel Time, and a Seat on a Bus. Rand Journal of Economics, Vol. 18, No. 1, 1987, pp. 40-56.

24. Wardman, M. Public Transport Values of Time. Transport Policy 11, Vol. 11, 2004, pp. 363-377.

25. Fan, W. and R. Machemehl. Do Transit Users Just Wait for Buses or Wait with Strategies?

Transportation Research Record: Journal of the Transportation Research Board, Vol. 2111, No. -1, 2009, pp. 169-176.

26. Hall, R. Passenger Waiting Time and Information Acquisition Using Automatic Vehicle Location for Verification. Transportation Planning and Technology, Vol. 24, 2001, pp. 249-269. 27. Hess, D., J. Brown and D. Shoup. Waiting for the Bus. Journal of Public Transportation, Vol. 7, No. 4, 2004, pp. 67-84.

28. Drew, K. and M. Rowe. Applying Accessibility Measures to Assess a Transport Intervention Strategy: A Case Study of Bromsgrove. Journal of Maps, Vol. 6, No. 1, 2010, pp. 181-191. 29. El-Geneidy, A., J. Strathman, T. Kimpel and D. Crout. The Effects of Bus Stop Consolidation on Passenger Activity and Transit Operations. Transportation Research Record: Journal of the Transportation Research Board, Vol. 1971, 2006, pp. 32-41.

30. Hensher, D. A., P. Stopher and P. Bullock. Service Quality-Developing a Service Quality Index in the Provision of Commercial Bus Contracts. Transportation Research Part A, Vol. 37, 2003, pp. 499-517.

31. Boyle, D. Fixed-Route Transit Ridership Forecasting and Service Planning Methods. TCRP Synthesis 66. Washington, DC, 2006.

32. Hollander, Y. Direct Versus Indirect Models for the Effects of Unreliability. Transportation Research Part A: Policy and Practice, Vol. 40, No. 9, 2006, pp. 699-711.

33. Zhao, F., L. Chow, M. Li, I. Ubaka and A. Gan. Forecasting Transit Walk Accessibility: Regression Model Alternative to Buffer Method. Transportation Research Record: Journal of the Transportation Research Board, No. 1835, 2003, pp. 34-41.

34. Murray, A. and X. Wu. Accessibility Tradeoffs in Public Transit Planning. Journal of Geographical Systems, Vol. 5, No. 1, 2003, pp. 93-107.

35. O'Neill, W., D. Ramsey and J. Chou. Analysis of Transit Service Areas Using Geographic Information Systems. Transportation Research Record, No. 1364, 1992, pp. 131-139.

36. Diab, E. and A. El-Geneidy. Understanding the Impacts of a Combination of Service Improvement Strategies on Bus Running Time and Passenger's Perception. Transportation Research Part A: Policy and Practice, Vol. 46, No. 3, 2012, pp. 614-625.

37. Diab, E. and A. El-Geneidy. Variation in Bus Transit Service: Understanding the Impacts of Various Improvement Strategies on Transit Service Reliability. Public Transport, Vol. 4, No. 3, 2013, pp. 209-231.

38. 
1 39. Tétreault, P. and A. El-Geneidy. Estimating Bus Run Times for New Limited-Stop Service 2 Using Archived Avl and Apc Data. Transportation Research: Part A, Vol. 44, No. 6, 2010, pp. 3 390-402.

4 